\title{
Dietary Protein Supplementation Increases Peak Bone Mass Acquisition in Energy-Restricted Growing Rats
}

\author{
JULIE MARDON, ANNA TRZECIAKIEWICZ, VÉRONIQUE HABAUZIT, MARIE-JEANNE DAVICCO, PATRICE LEBECQUE, \\ SYLVIE MERCIER, JEAN-CLAUDE TRESSOL, MARIE-NOËLLE HORCAJADA, CHRISTIAN DEMIGNÉ, \\ AND VÉRONIQUE COXAM
}

Unité de Nutrition Humaine UMR1019, INRA Clermont-Ferrand/Theix, 63122 Saint Genès Champanelle, France

\begin{abstract}
Peak bone mass is a major determinant of osteoporosis pathogenesis during aging. Respective influences of energy and protein supplies on skeletal growth remains unclear. We investigated the effect of a 5-mo dietary restriction on bone status in young rats randomized into six groups ( $n=10$ per group). Control animals were fed a diet containing a normal (13\%) (C-NP) or a high-protein content (26\%) (C-HP). The other groups received a $40 \%$ protein energy-restricted diet (PER-NP and PER-HP) or a $40 \%$ energyrestricted diet (ER-NP and ER-HP). High-protein intake did not modulate bone acquisition, although a metabolic acidosis was induced and calcium retention impaired. PER and ER diets were associated with a decrease in femoral bone mineral density. The compensation for protein intake in energy-restricted conditions induced a bone sparing effect. Plasma osteocalcin (OC) and urinary deoxypyridinoline (DPD) assays revealed a decreased OC/DPD ratio in restricted rats compared with $\mathrm{C}$ animals, which was far more reduced in PER than in ER groups. Circulating IGF-1 levels were lowered by dietary restrictions. In conclusion, both energy and protein deficiencies may contribute to impairment in peak bone mass acquisition, which may affect skeleton strength and potentially render individuals more susceptible to osteoporosis. (Pediatr Res 66: 513-518, 2009)
\end{abstract}

$\mathrm{T}^{\mathrm{s}}$ he amount of bone accumulated at the end of skeletal growth is a major determinant of osteoporosis development and fracture risk during aging. Even if genetics seem to account for most of the variance of bone mass, nutritional intakes have been identified as critical factors impacting skeletal modeling and maturation.

In particular, alterations in energy intake have been demonstrated to impair bone quality and strength in rodent models (1-5). Lamothe et al. (1) and Mardon et al. (2) reported that energy restriction adversely affected bone mineral content (BMC), bone mineral density (BMD), and mechanical properties in old rats, despite a micronutrient compensation. Nevertheless, the impact of energy restriction on bone was suggested to be modulated by the age at onset of restriction $(5,6)$. To date, no clear consensus regarding the effects of energy restriction on peak bone mass acquisition has been established.

Protein intake is widely linked to bone growth, hence to bone strength (7). Indeed, collagen is the major constituent of bone organic matrix, and noncollagenic proteins are involved in the regulation of the mineralization process. Dietary pro-

Received March 26, 2009; accepted June 17, 2009

Correspondence: Julie Mardon, Ph.D., Unité Typicité des Produits AlimentairesDépartement Qualité et Economie Alimentaires, Enita Clermont-Site de Marmilhat BP 35, 63370 Lempdes, France; e-mail: mardon@enitac.fr teins provide the essential amino acids necessary for new matrix synthesis and may modulate circulating IGF-1 levels as well, an osteotrophic growth factor (8). In growing animals, protein deficiency was demonstrated to lead to decreased bone status (9). Ammann et al. (10) also reported that a $2.5 \%$ casein diet during $16 \mathrm{wk}$ in 5-mo-old rats was associated with bone loss.

Consequently, one would expect high-protein intake to promote bone health. However, other reports suggest that such a diet may alter calcium homeostasis in ways that could lead to bone loss $(11,12)$. The metabolic acidosis, derived from sulfur amino acids catabolism, would also exert a direct stimulatory effect on bone resorption and an inhibitory action on matrix mineralization $(13,14)$. Actually, the role of dietary protein on bone remains controversial.

In the current context of rising incidence of obesity in adolescents, low-energy diets associated with high-protein intakes are widely used in weight management programs. Thus, further investigations would be needed to completely define the role of high- or low- protein intake on both the acid-base metabolism and bone mass acquisition in young individuals and to determine the respective roles of energy and protein intakes on skeletal growth. This study, conducted in young rats, was designed to address two specific questions:

i. Does a high-protein diet (HP, 26\%) induce beneficial or detrimental effects on bone acquisition compared with a normal-protein diet (NP, 13\%)?

ii. What are the consequences on peak bone mass of a 5-mo period of protein and energy restriction (PER) and energy restriction (ER) alone compared with a control protein and energy supply (C)?

\section{MATERIALS AND METHODS}

Experimental design. The study was approved by the Ethics Committee on animal experiments of Auvergne, in France.

Sixty Wistar male rats (10 wk old, average weight $394 \mathrm{~g}$ ) were purchased from INRA (Institut National de la Recherche Agronomique, ClermontFerrand/Theix, France). The animals were housed individually in cages. They were subjected to 12-/12-h light/dark cycles and had free access to water. Their body weight and food intake were measured weekly.

Abbreviations: BMD, bone mineral density; $\mathbf{C}$, treatment with control diet; DPD, deoxypyridinoline; ER, treatment with energy-restricted diet; HP, treatment with high-protein intake diet; NP, treatment with normal protein intake diet; OC, osteocalcin; PER, treatment with protein energy-restricted diet 
Table 1. Daily ration composition

\begin{tabular}{lcccccc}
\hline Component $(\mathrm{g} / \mathrm{d})$ & $\mathrm{C}-\mathrm{NP}$ & $\mathrm{C}-H P$ & PER-NP & PER-HP & ER-NP & ER-HP \\
\hline Casein & 2.99 & 5.98 & 1.82 & 3.64 & 3.01 & 6.04 \\
Corn starch & 13.27 & 10.83 & 6.97 & 5.50 & 6.02 & 3.55 \\
Sucrose & 3.31 & 2.71 & 1.75 & 1.37 & 1.50 & 0.88 \\
Groundnut and & 1.39 & 1.39 & 1.40 & 1.40 & 1.40 & 1.40 \\
$\quad$ rape oils & & & & & & \\
Cellulose & 0.92 & 0.92 & 0.92 & 0.92 & 0.92 & 0.92 \\
L-cystin & 0.045 & 0.090 & 0.027 & 0.055 & 0.045 & 0.091 \\
Choline bitartrate & 0.058 & 0.058 & 0.059 & 0.059 & 0.059 & 0.059 \\
Mineral mix* & 0.80 & 0.80 & 0.81 & 0.81 & 0.81 & 0.81 \\
Vitamin mix $\dagger$ & 0.23 & 0.23 & 0.23 & 0.23 & 0.23 & 0.23 \\
Total daily intake & 23 & 23 & 14 & 14 & 14 & 14 \\
\hline
\end{tabular}

* Expressed in $\mathrm{g} / \mathrm{kg}$ of mixture: $\mathrm{CaCO}_{3}, 178.5 ; \mathrm{KH}_{2} \mathrm{po}_{4}, 250 ; \mathrm{K}_{3} \mathrm{C}_{6} \mathrm{H}_{5} \mathrm{O}_{7}$, 28.00; NaCl, 74; $\mathrm{K}_{2} \mathrm{SO}_{4}, 46.60 ; \mathrm{MgO}, 24.00 ; \mathrm{FeC}_{6} \mathrm{H}_{8} \mathrm{O}_{7}, 6.06 ; \mathrm{ZnCO}_{3}, 1.65$; $\mathrm{Na}_{2} \mathrm{SiO}_{3} \cdot 9 \mathrm{H}_{2} \mathrm{O}, 1.45 ; \mathrm{MnCO}_{3}, 0.63 ; \mathrm{CuCO}_{3}, 0.30 ; \mathrm{CrKO}_{8} \mathrm{~S}_{2} \cdot 12 \mathrm{H}_{2} \mathrm{O}, 0.275$; $\mathrm{H}_{3} \mathrm{BO}_{3}, 0.0815 ; \mathrm{FNa}, 0.0635 ; \mathrm{NiCO}_{3}, 0.0318$; LiCl, 0.0174; $\mathrm{Na}_{2} \mathrm{SeO}_{4}$, $0.01025 ; \mathrm{KIO}_{3}, 0.010 ;\left(\mathrm{NH}_{4}\right)_{6} \mathrm{Mo}_{7} \mathrm{O}_{24} \cdot 4 \mathrm{H}_{2} \mathrm{O}, 0.00795 ; \mathrm{NH}_{4} \mathrm{VO}_{3}, 0.0066$.

$\dagger$ Expressed in $\mathrm{g} / \mathrm{kg}$ of mixture: nicotinic acid, 3.000; calcium pantothenate, 1.600; pyridoxine-HCL, 0.700; thiamine-HCL, 0.600; riboflavin, 0.6000; folic acid, 0.200; biotin, 0.020; cyanocobalamin, 2.500; all-rac- $\alpha$-tocopheryl acetate $(500 \mathrm{IU} / \mathrm{g}), 5.000$; all-trans-retinyl palmitate (500000 IU/g), 0.800; cholecalciferol (400000 IU/g), 0.083; phylloquinone, 0.075 .

At the beginning of the study, the rats were randomly allocated to one of six dietary groups ( $n=10$ rats/group). Two control groups (C) received a standard semipurified diet containing either a normal protein content $(13 \%)$ (C-NP) or a high-protein content (26\%) (C-HP). The ad libitum food intake of $\mathrm{C}$ groups was determined during $1 \mathrm{wk}$ of adaptation $(\mathrm{C}-\mathrm{NP}, 24.9 \pm 0.8 \mathrm{~g}$ versus $\mathrm{C}-\mathrm{HP}, 24.1 \pm 0.7 \mathrm{~g}$ ). Then, rats of the $\mathrm{C}$ groups were fed a measured amount of diet, corresponding to $90-95 \%$ of the average ad libitum intake of C-HP group, which had the lowest food intake to match caloric intake and to facilitate the study of healthy, nonobese $\mathrm{C}$ animals, as recommended by Pugh et al. (15). The mean energy intake of C groups was about $380 \mathrm{~kJ} / \mathrm{d}$ (91 kcal/d) (Table 1). The protein and energy-restricted groups (PER-NP and PER-HP) were limited to $60 \%$ of the intake of the $\mathrm{C}$ groups [i.e. 7.8 and $15.6 \%$ protein, respectively and $228 \mathrm{~kJ} / \mathrm{d}(55 \mathrm{kcal} / \mathrm{d})]$. The energy-restricted groups (ER-NP and ER-HP) received $40 \%$ less energy than the controls (i.e. $228 \mathrm{~kJ} / \mathrm{d}$ ), but had their protein intake maintained at the level of the $\mathrm{C}$ groups. All diets were purchased from INRA (Jouy en Josas, France). Diet-restricted rats were normalized to the $\mathrm{C}$ animals with respect to lipids, fibers, minerals, and vitamins intake. Thus, all the animals consumed the same amounts of calcium (around $58 \mathrm{mg} \mathrm{Ca} / \mathrm{d}$ ) and phosphorus (around $46 \mathrm{mg} \mathrm{P} / \mathrm{d}$ ).

After $5 \mathrm{mo}$, the rats were killed. One week before sacrifice, the rodents were transferred to individual metabolic cages. After a 3-d adaptation period, food intake was daily controlled, and urine and faeces were collected for 3 consecutive days. At the end of the experiment, the animals were fasted for $12 \mathrm{~h}$ and then killed. Blood samples were collected from the abdominal aorta, and plasma was frozen at $-20^{\circ} \mathrm{C}$ until biochemical analysis. Femurs were cleaned from adjacent tissues. Left femurs were harvested in saline solution ( 9 $\mathrm{g} \mathrm{NaCl} / \mathrm{L})$ and frozen $\left(-20^{\circ} \mathrm{C}\right)$ until mechanical testing. Right femurs were kept in $80 \%$ alcohol until BMD measurements.

Analysis. Calcium and magnesium concentrations in food, urine, and faecal samples were determined by atomic absorption spectrophotometry (AA800, Perkin Elmer, Norwalk, CT), as described previously (16). Then, calcium retention $(\mu \mathrm{mol} / 24 \mathrm{~h})$, defined as [calcium intake - (urinary calcium excretion + faecal calcium excretion)] was calculated.

Urines were 400 -fold diluted with milli-Q water. Phosphate, sulfate, and citrate concentrations were assayed by ionic chromatography (DX320, Dionex, Sunnydale, CA) (16).

IGF-1 concentrations were measured in serum samples using a two-site immunoenzymometric assay (OCTEIA Rat/Mouse IGF-1 kit, IDS, Paris, France). The sensitivity of the assay was $82 \mathrm{ng} / \mathrm{mL}$. Intra and interassay variations were 5.7 and $10.7 \%$, respectively.

Plasma osteocalcin (OC) concentrations were measured by immunoradiometric assay (Immunotopics, Inc., San Clemente, CA). The sensitivity was $0.01 \mathrm{ng} / \mathrm{mL}$. The intra and interassay precisions were 2.0 and $4.5 \%$, respectively. The urinary deoxypyridinoline (DPD) concentration (nmol/L) was determined by competitive RIA (Pyrilinks-D RIA kit, Metra Biosystems, Mountain View, CA). The sensitivity was $2 \mathrm{nmol} / \mathrm{L}$. The intra and interassay precisions were 4 and $6 \%$, respectively. DPD excretion rate $(\mathrm{nmol} / 24 \mathrm{~h})$ was calculated using the previous 24 -h urine volumes.
BMD was assessed by dual-energy $\mathrm{x}$-ray absorptiometry, using a Hologic QDR-4500 A x-ray bone densitometer (Hologic, Massy, France). Total femoral BMD (T-BMD), metaphyseal BMD (M-BMD), and diaphyseal BMD (D-BMD) were determined. Scans were cut and analyzed as follow: the first cut of the femur was performed at the upper quarter, and the next cut at the lower quarter. D-BMD, which contains a high percentage of cortical structure, corresponded to the density of the second and the third quarter of the femur. M-BMD, which mainly contains trabecular structure, was calculated as the mean of the upper and the lower quarters of the femur.

Femoral length and mean diaphyseal diameter were measured with a precision caliper (Mitutoyo, Shropshire, UK). The femoral failure load was then determined using a 3-point bending test, with a Universal Testing Machine (Instron 4501, Instron, Canton, MA). The two lower supports were separated by a $20-\mathrm{mm}$ distance, and an upper crosshead roller (diameter, 6 $\mathrm{mm}$ ) was applied in front of the middle of the bone at a speed of $0.5 \mathrm{~mm} / \mathrm{min}$ until failure. Load (Newtons) at rupture was recorded.

Statistical methods. Results are expressed as the mean \pm SEM and were analyzed with XLSTAT (Addinsoft, Paris, France). The BMD, biomechanical and histomorphometric variables were subjected to a two-way analysis of covariance (ANCOVA) with body weight as the covariate (17). Other parameters were analyzed using a two-way ANOVA, testing for any difference among groups. Thus, the main assessed effects were dietary restriction (C/PER/ER), protein intake (NP/HP), and their interaction (dietary restriction $\times$ protein intake). If a result was found significant $(p<0.05)$, the Student-Newman-Keuls multiple comparison test was used to determine specific differences between means. Linear regressions were also performed, to study internal correlations among variables, and the Pearson test was carried out to assess their significance.

\section{RESULTS}

Body weight. In C-NP and C-HP groups, body weight increased by $28 \%$ during the experimental period (Fig. 1). PER and ER rats on the NP diets exhibited a constant body weight, whereas a significant increase was registered in PER-HP and ER-HP groups ( +6 and $+11 \%$, respectively). At the end of the study, restricted animals exhibited a lower body weight $(p<0.0001)$ than controls.

Daily calcium ration. Calcium concentrations measured by atomic absorption spectrophotometry in the diets confirmed that all groups received an identical calcium ration $(\mathrm{mg} \mathrm{Ca} /$ daily ration) (C-NP, $59.0 \pm 2.3$; C-HP, $58.5 \pm 2.7$; PER-NP, $57.9 \pm 1.9$; PER-NP, 58.3; PER-HP, 2.6; ER-NP, $57.8 \pm 2.0$; ER-HP, $58.6 \pm 2.5$ ).

Urine cation and anion excretion. After $20 \mathrm{wk}$ of experiment, urinary $\mathrm{pH}$ was acidic in all animals (Table 2). Significant differences were recorded among groups $(p<0.0001)$.

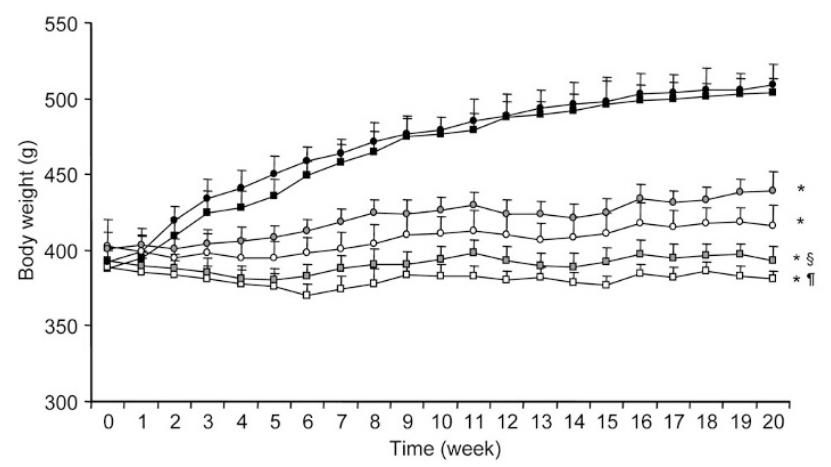

Figure 1. Body weight of rats fed control diets (C-NP ( $\square)$ and C-HP (๑)), protein caloric-restricted diets (PER-NP $(\square)$, PER-HP $(\bigcirc)$ ), and caloricrestricted diets (ER-NP (ם), ER-HP (๑)) during the experimental period. *Significantly different from $\mathrm{C}$ groups $(p<0.05)$. §Significantly different from ER-HP group $(p<0.05)$. I[Significantly different from PER-NP and PER-HP groups $(p<0.05)$. 
Table 2. Effect of dietary restrictions $(C / P E R / E R)$ and the level of protein intake $(N P / H P)$ on urine $\mathrm{pH}$, urinary calcium, magnesium, sulfate, phosphate and citrate excretions

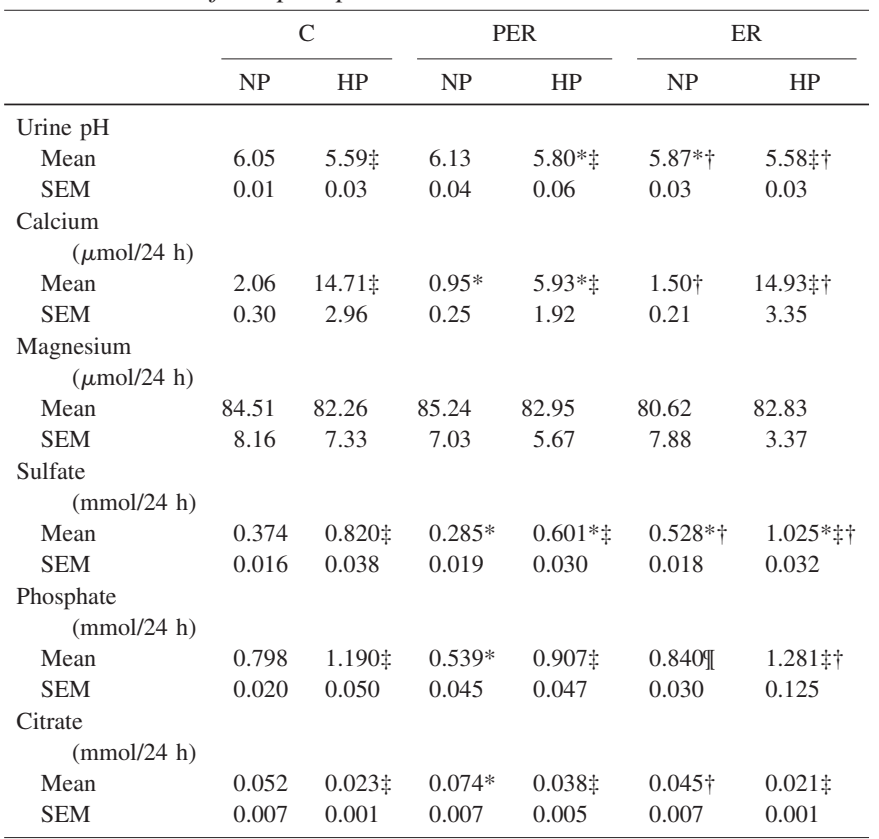

Values are expressed as means \pm SEM.

* Significantly different from C group with a similar level of protein intake for a given variable $(p<0.05)$.

$\dagger$ Significantly different from PER group with a similar level of protein intake for a given variable $(p<0.05)$.

\$ Significantly different from NP group with a similar dietary restriction for a given variable $(p<0.05)$.

Rats adapted to the HP diets showed lower urinary $\mathrm{pH}$ than those receiving the NP diets. Moreover, PER groups exhibited higher urinary $\mathrm{pH}$, whereas ER rats had more acidic urines than controls. Urinary calcium excretion displayed a 6- to 10-fold rise in rats fed the HP diets compared with those fed the NP diets, and calciuria was lower in PER groups than in C and ER rats. Sulfate and phosphate excretions increased with the HP diets compared with the NP diets. They were both lowered in PER groups compared with C rats. Sulfate excretion was increased in all energy restriction animals. In contrast, renal citrate excretion was lower in HP than in NP groups for a given type of dietary restriction. PER groups excreted more citrate compared with $\mathrm{C}$ rats. Magnesium excretion did not vary.

Calcium retention. At the end of the study, calcium retention was positive in the $\mathrm{C}$ groups (Fig. 2). PER and ER groups showed a negative calcium retention compared with $\mathrm{C}$ animals $(p<0.0001)$. Moreover, HP diets were associated with even lower calcium retentions compared with NP diets $(p=0.001)$.

Bone mineral density. The BMD was lower in both PER and ER rats compared with $C$ rats in total femur $(p=0.015)$ and at metaphysal $(p=0.009)$ and diaphysal $(p=0.060)$ sites (Fig. $3 A-C$ ). ER groups exhibited a significantly higher femoral BMD than PER animals. No difference was recorded between NP and HP groups.

Femoral sizes and biomechanical properties. $\mathrm{PER}$ and $\mathrm{ER}$ femur length $(\mathrm{mm})$ was shorter than that of $\mathrm{C}$ femurs (C-NP, $39.67 \pm 0.30$; C-HP, $40.10 \pm 0.37$ versus PER-NP, $38.06 \pm$ 0.43 ; PER-HP, $38.38 \pm 0.44$; ER-NP, $38.45 \pm 0.46$; ER-HP,

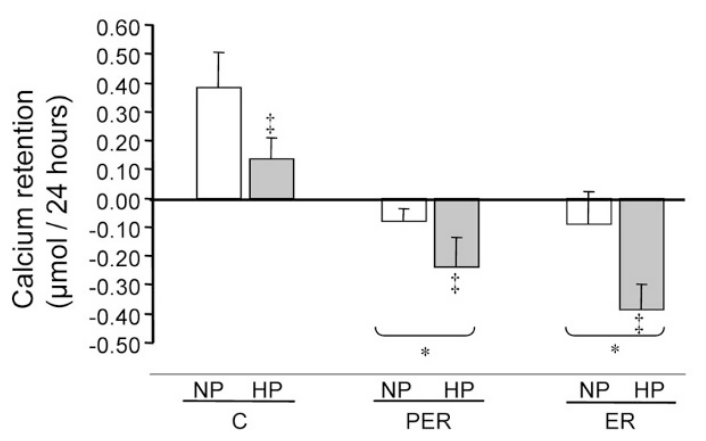

Figure 2. Effect of dietary restrictions (C/PER/ER) and the level of protein intake (NP/HP) on calcium retention $(\mu \mathrm{mol} / 24 \mathrm{~h})$. *Significantly different from $\mathrm{C}$ groups. $\ddagger$ Significantly different from NP groups.

$38.68 \pm 0.33)$. These variations accounted for body weight changes because no difference was recorded by ANCOVA analysis. Femur diameter did not vary.

Femoral biomechanical values displayed some similar features to BMD results, which was confirmed by a high positive correlation between fracture load and T-BMD data $(r=0.618$, $p<0.0001$ ). Biomechanical properties tended to be lower in PER and ER groups compared with $\mathrm{C}$ groups, even though no significant difference was recorded (Fig. 3D).

Bone biomarkers. At the end of the experiment, plasma OC was reduced in PER groups $(p=0.039)$ compared with $C$ groups (Fig. 4A). A similar pattern was observed in ER animals. Urinary DPD excretion rate was lower in both restricted conditions (PER and ER) than in controls $(p<$ 0.0001) (Fig. 4B). The OC/DPD ratio (\%) (C-NP, $26.21 \pm$ 2.95; C-HP, $23.65 \pm 1.75$; PER-NP, $16.24 \pm 3.14$; PER-HP, $16.31 \pm 3.06$; ER-NP, $22.09 \pm 4.15$; ER-HP, $19.54 \pm 2.07$ ), indicating the level of bone remodelling, was reduced by about $7-10 \%$ in PER animals compared with $\mathrm{C}$ rats, whereas it was only $4 \%$ lower in ER groups. Bone biomarkers were not significantly modulated by the level of protein intake (NP or HP).

Plasma IGF-1. Plasma IGF-1 concentrations were lower in the PER and ER groups compared with the $\mathrm{C}$ animals $(p<$ 0.0001 ) (Fig. 5). IGF-1 levels increased by 4 to $6 \%$ between the NP and the HP groups (non significant).

\section{DISCUSSION}

The respective influences of energy and dietary protein intakes on peak bone mass acquisition are not clearly identified. The present investigation allowed to examine the effect of a high-protein intake (HP, 26\%) compared with a normal intake (NP, 13\%), on bone acquisition in young male rats, and to differentiate the impact of PER and ER. On the basis previous works $(2,3,5,18)$, our study involved a level of restriction of $40 \%$. Dietary restriction was initiated at $10 \mathrm{wk}$ of age and continued for 5 mo. Peak bone mass is achieved at nearly 9 mo of age in rats (19). Thus, the animals were growing throughout the whole experimental period.

During the experimental period, restricted animals (PER and ER) exhibited little variations in their body weight, whereas groups fed the $\mathrm{C}$ diets markedly gained mass. In 

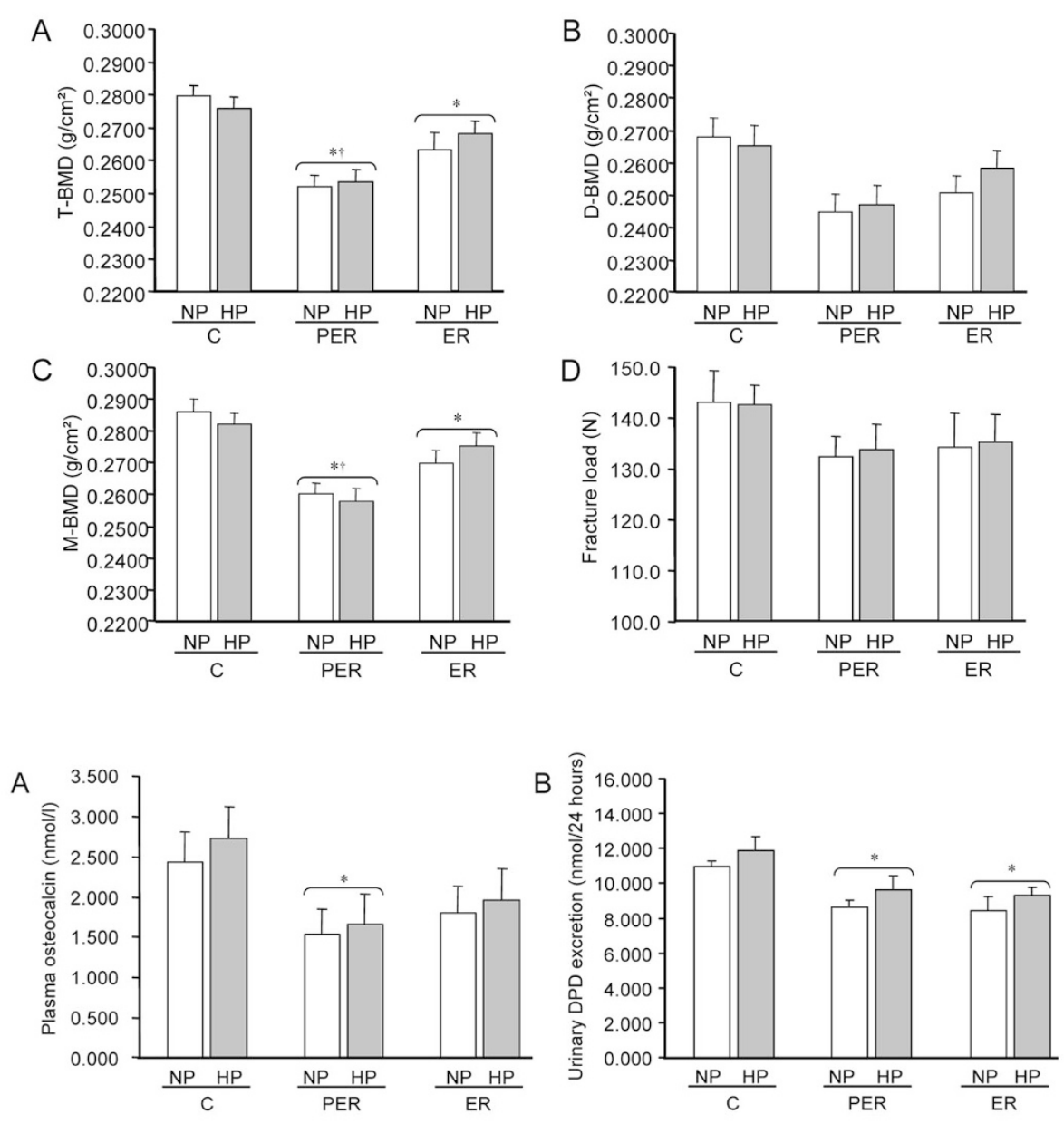

Figure 3. Effect of dietary restrictions (C/PER/ $\mathrm{ER})$ and the level of protein intake (NP/HP) on total (T-BMD) (A), diaphysal (D-BMD) $(B)$, metaphysal (M-BMD) $(C)$ femoral BMD, and biomechanical resistance $(D)$. *Significantly different from $\mathrm{C}$ groups. $†$ Significantly different from ER groups.
Figure 4. Effect of dietary restrictions (C/PER/ $\mathrm{ER})$ and the level of protein intake (NP/HP) on plasma OC $(A)$ and the urinary DPD excretion rate $(B) .{ }^{*}$ Significantly different from $\mathrm{C}$ groups.

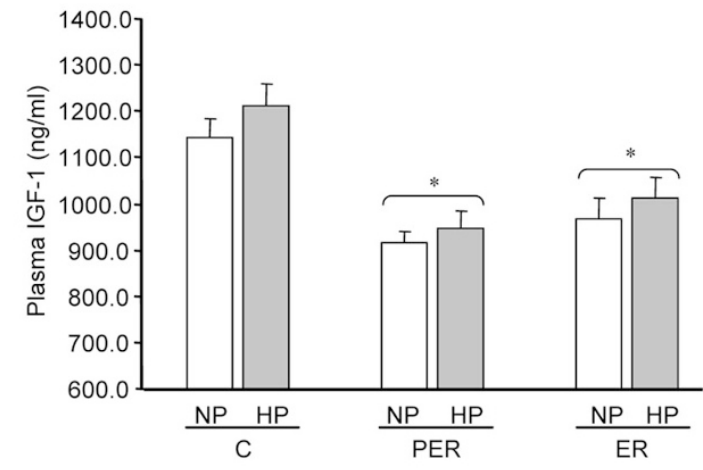

Figure 5. Effect of dietary restrictions (C/PER/ER), and the level of protein intake (NP/HP) on plasma IGF-1 concentrations. *Significantly different from C groups.

adequate conditions of energy supply ( $\mathrm{C}$ groups), the protein content of the diet had no effect on body weight. However, among energy-restricted rats, relative lower body weights were recorded, according to the decreased level of protein intake. Body weight variations are recognized to result in bone mass modulations $(4,5)$. To address the effects of the dietary restrictions and the level of protein intake independently of body weight changes, body weight was included as an independent variable in the statistical analysis of bone parameters (17).
Urine $\mathrm{pH}$ was acidic in all groups. Nevertheless, HP diets elicited a greater acid load, characterized by a decrease in urine $\mathrm{pH}$ compared with NP diets. Urinary acidification induced a marked rise of calciuria, whereas renal magnesium excretion was not affected. Hypercalciuria is a well-known consequence of high-protein diets (11), resulting from the neutralization of the $\mathrm{SO}_{4}{ }^{2-}$ generated by sulfur amino acids catabolism. In the kidney, it was attributed to an increased GFR and a decreased tubular calcium reabsorption. A rise in both urinary sulfate and phosphate excretion rates was reported in the HP groups. These increases were likely due to greater contents of sulfur amino acids and organic phosphorus, respectively, in the HP diets (20). Hypocitraturia, also associated with high-protein intakes (12), was observed in the HP groups, as well, as a consequence of a decrease in proximal tubule reabsorption of citrate and an impairment of citrate transport in the kidney (20).

The type of restriction (C, PER, or ER) also resulted in urinary parameters changes. Protein deficiency induced higher urinary $\mathrm{pH}$ and citrate excretion and lower urinary calcium, sulfate, and phosphate excretions. In the ER diets, there was no change in such parameters compared with the $\mathrm{C}$ diets, and sulfate excretion rate was even increased, as a result of a relative high concentration of protein in the mean daily ration.

Calcium retention was decreased significantly by the highprotein $(26 \%)$ diets. Conversely, some studies in rats found no 
effect of high-protein intake on intestinal calcium absorption (21). However, the durations of these studies were shorter. In this study, calcium retention was far more affected by energy restriction.

$\mathrm{C}$ rats provided with a higher protein level in the diet (C-HP versus $\mathrm{C}-\mathrm{NP}$ ) exhibited no noticeable changes in their femoral $\mathrm{BMD}$, biomechanical properties, or bone remodelling biomarkers. These results are consistent with previous observations in rats $(16,21)$ that reported no change in femoral bone mass, macro-mineral composition, or urinary excretion of pyridinium crosslinks of collagen in response to a dietary protein excess, despite hypercalciuria. Zernicke et al. (22) found a greater femoral neck percent ash in 8-wk-old rats fed a $30 \%$ protein diet (versus 15\%), however, without any improvement regarding structural and material properties. Although the reciprocal response of osteoclasts and osteoblasts to metabolic acidosis has been shown to potentially affect bone metabolism $(13,14)$, the dietary acid load generated by higher protein intakes (HP diets versus NP diets and C/ER diets versus PER diets) had no consequences. No change was recorded in plasma IGF-1 levels between the C-HP and the C-NP groups, even though it is known to be modulated by protein intake (8). Actually, it is likely that the present range of variation in protein intake was not sufficiently wide to detect changes in the stimulating effect it exerts on IGF-1 levels. Thus, all bone parameters concur to conclude that the low-grade metabolic acidosis induced by the hyperproteic diet did not affect the skeleton.

In contrast to the numerous reports of beneficial effects of protein intake on bone (23), some authors support that a high-protein diet would alter bone health (24,25). Amanzadeh et al. (12) observed a bone loss, based on histomorphometric analysis, in rats fed a $48 \%$ casein diet during $59 \mathrm{~d}$ and displaying hypercalciuria and hypocitraturia. This was not relevant with our observations. Actually, it seems that whether dietary protein has a beneficial or detrimental effect on bone also depends on additional nutritional factors, such as calcium intake. An adequate calcium supply, as in this experiment, was suggested to erase the negative effect of protein on bone mass (26). Nevertheless, it remains possible that a diet substantially higher with reduced calcium intake in protein will cause deleterious effects on bone.

Dietary restrictions did not affect bone growth in width. Femurs were longer in $\mathrm{C}$ groups compared with restricted rats. However, the normalization for total body weight erased any variations, suggesting that bone growth in length was only influenced by the increased mechanical loading associated with body weight gain, rather than by the diet itself.

Regarding bone status, ultimate femoral BMD was lower in energy (ER) and protein energy-restricted (PER) animals, than in the $\mathrm{C}$ groups. At the diaphyseal site, femoral biomechanical properties were highly correlated with BMD values $(r=$ $0.618, p<0.0001$ ) and tended to be impaired by the two types of restriction. As previously reported, this observation might also be attributed to decreased diaphyseal cortical area, which contributes to bone fragility (3). Similarly, Talbott et al. (18) observed decreased BMD and BMC, respectively, in rats after 9 and 16 wk of $40 \%$ energy restriction. Sanderson et al. (4) also reported a detrimental effect of dietary restriction on bone in rats but only attributed to body weight variation. In contrast, the results of our ANCOVA support the view that BMD variations are not related to body weight reduction. This is consistent with the study of LaMothe et al. (1), who demonstrated that the impaired tibia structural properties associated with ER were independent of body mass. Therefore, dietaryinduced modulation of bone metabolism and hormonal factors are likely to contribute to the BMD variations.

The single restriction in energy was associated with significantly higher femoral BMD than with the PER diets. This suggests that protein and energy deficiencies would have additional detrimental effects on bone status acquisition. The compensation for protein intake in energy-restricted conditions induced a less pronounced bone alteration. Similarly, Bourrin et al. (27) reported a decrease in BMD in 6-mo-old rats in response to protein deficiency. Moreover, young rats fed a protein deficient diet for $20 \mathrm{~d}$ exhibited lower femoral diaphyseal bending stiffness and breaking strength (9). In agreement with our results, Ammann et al. (10) showed that the consumption of an isocaloric essential amino acid supplement was able to correct the bone alterations induced by a low-protein diet in female ovariectomized rats.

BMD changes may be explained by modulations in bone remodelling. Indeed, energy restriction lowered DPD levels in a significant manner, whereas an additional restriction in protein supply decreased both OC and DPD levels. Thus, the OC/DPD ratio was far more reduced in PER than in ER groups, compared with $\mathrm{C}$ rats, which was consistent with the BMD data. Nevertheless, the exact impact of dietary restrictions on bone biomarkers remains unclear, given the conflicting results observed in previous reports $(5,17,27)$.

The decrease in plasma IGF-1 levels associated with dietary restrictions (PER and ER) probably played a role on the femoral BMD and bone biomarkers modulations. Nutritional status is a critical factor in the regulation of circulating IGF-1 levels (8). Given its anabolic effect on bone and on epiphyseal cartilage, IGF-1 is determinant for bone growth. Low energy and protein intakes could be detrimental for skeletal integrity by lowering to an inadequate level the production of IGF-1, which could be directly implicated in bone matrix mineralization. It is also possible that circulating levels of IGFBP-1 were modified in response to changes in nutrient supplies, which was suggested to modulate IGF-1 bioavailability by competing for IGF-1 binding with the IGF-1 receptor (28). Despite no significance of difference, IGF-1 levels tended to be higher in ER groups compared with PER animals. This pattern was consistent with the increased femoral BMD induced by the supplementation of protein intake in an energy-restricted context compared with PER conditions. Indeed, elevated protein intake has been shown to be able to prevent the decrease in IGF-1, usually observed in hypocaloric states (29).

The age-sensitive response to energy and protein restriction suspected by Talbott et al. (18) was confirmed. Indeed, in contrast with our previous findings in old rats $(2,3)$, dietary restrictions did not induce body weight loss but only erased weight gain, suggesting a slowing down of the growth rate. The supplementation of dietary protein limited the bone loss 
due to energy deficiency, whereas it failed to improve bone status in old rats.

As a conclusion, neither beneficial nor detrimental effects associated with a high-protein intake were reported on bone status, despite an induction of metabolic acidosis and an impairment on calcium retention. Regarding dietary restrictions, decreased energy and protein intakes markedly affected bone status in growing rats. Such nutritional deficiencies might contribute to impairment on peak bone mass acquisition and affect skeleton strength throughout later life, potentially rendering the individual more susceptible to osteoporosis. Our study also demonstrated a significant bone sparing effect when ER was associated with an adequate protein intake. Thus, great care should be taken regarding the respective energy and protein supplies during growth, particularly when setting up weight management programs intended for obese adolescents.

\section{REFERENCES}

1. LaMothe JM, Hepple RT, Zernicke RF 2003 Selected contribution: bone adaptation with aging and long-term caloric restriction in Fischer $344 \times$ Brown-Norway F1-hybrid rats. J Appl Physiol 95:1739-1745

2. Mardon J, Habauzit V, Trzeciakiewicz A, Davicco MJ, Lebecque P, Mercier S, Tressol JC, Horcajada MN, Demigne C, Coxam V 2008 Influence of high and low protein intakes on age-related bone loss in rats submitted to adequate or restricted energy conditions. Calcif Tissue Int 82:373-382

3. Mardon J, Zangarelli A, Walrand S, Davicco MJ, Lebecque P, Demigne C, Horcajada MN, Boirie Y, Coxam V 2008 Impact of energy and casein or whey protein intake on bone status in a rat model of age-related bone loss. Br J Nutr 99:764-772

4. Sanderson JP, Binkley N, Roecker EB, Champ JE, Pugh TD, Aspnes L, Weindruch $\mathrm{R} 1997$ Influence of fat intake and caloric restriction on bone in aging male rats. J Gerontol A Biol Sci Med Sci 52:B20-B25

5. Talbott SM, Rothkopf MM, Shapses SA 1998 Dietary restriction of energy and calcium alters bone turnover and density in younger and older female rats. J Nutr 128:640-645

6. Lambert J, Lamothe JM, Zernicke RF, Auer RN, Reimer RA 2005 Dietary restriction does not adversely affect bone geometry and mechanics in rapidly growing male wistar rats. Pediatr Res 57:227-231

7. Rizzoli R, Bonjour JP, Chevalley T 2007 Dietary protein intakes and bone growth. Int Congr Ser 1297:50-59

8. Thissen JP, Ketelslegers JM, Underwood LE 1994 Nutritional regulation of the insulin-like growth factors. Endocr Rev 15:80-101

9. Ferretti JL, Capozza R, Cointry G, Bozzini C, Alippi RM, Bozzini CE 1991 Additive effects of dietary protein and energy deficiencies on diaphysis and bone tissue of rat femurs as determined by bending tests. Acta Physiol Pharmacol Ther Latinoam 41:253-262

10. Ammann P, Laib A, Bonjour JP, Meyer JM, Ruegsegger P, Rizzoli R 2002 Dietary essential amino acid supplements increase bone strength by influencing bone mass and bone microarchitecture in ovariectomized adult rats fed an isocaloric low-protein diet. J Bone Miner Res 17:1264-1272

11. Chan EL, Swaminathan R 1994 The effect of high protein and high salt intake for 4 months on calcium and hydroxyproline excretion in normal and oophorectomized rats. J Lab Clin Med 124:37-41

12. Amanzadeh J, Gitomer WL, Zerwekh JE, Preisig PA, Moe OW, Pak CY, Levi M 2003 Effect of high protein diet on stone-forming propensity and bone loss in rats. Kidney Int 64:2142-2149

13. Arnett TR 2007 Acid-base regulation of bone metabolism. Int Congr Ser 1297:255267

14. Krieger NS, Frick KK, Bushinsky DA 2004 Mechanism of acid-induced bone resorption. Curr Opin Nephrol Hypertens 13:423-436

15. Pugh TD, Klopp RG, Weindruch R 1999 Controlling caloric consumption: protocols for rodents and rhesus monkeys. Neurobiol Aging 20:157-165

16. Mardon J, Habauzit V, Trzeciakiewicz A, Davicco MJ, Lebecque P, Mercier S, Tressol JC, Horcajada MN, Demigne C, Coxam V 2008 Long-term intake of a high-protein diet with or without potassium citrate modulates acid-base metabolism, but not bone status, in male rats. J Nutr 138:718-724

17. Lane MA, Black A, Handy AM, Shapses SA, Tilmont EM, Kiefer TL, Ingram DK, Roth GS 2001 Energy restriction does not alter bone mineral metabolism or reproductive cycling and hormones in female rhesus monkeys. J Nutr 131:820-827

18. Talbott SM, Cifuentes M, Dunn MG, Shapses SA 2001 Energy restriction reduces bone density and biomechanical properties in aged female rats. J Nutr 131:2382 2387

19. Wang L, Banu J, McMahan CA, Kalu DN 2001 Male rodent model of age-related bone loss in men. Bone 29:141-148

20. Sabboh H, Coxam V, Horcajada MN, Remesy C, Demigne C 2007 Effects of plant food potassium salts (citrate, galacturonate or tartrate) on acid-base status and digestive fermentations in rats. Br J Nutr 98:72-77

21. Creedon A, Cashman KD 2000 The effect of high salt and high protein intake on calcium metabolism, bone composition and bone resorption in the rat. Br J Nutr $84: 49-56$

22. Zernicke RF, Salem GJ, Barnard RJ, Woodward JS Jr, Meduski JW, Meduski JD 1995 Adaptations of immature trabecular bone to exercise and augmented dietary protein. Med Sci Sports Exerc 27:1486-1493

23. Bonjour JP, Ammann P, Chevalley T, Rizzoli R 2001 Protein intake and bone growth. Can J Appl Physiol 26:S153-S166

24. Sellmeyer DE, Stone KL, Sebastian A, Cummings SR 2001 A high ratio of dietary animal to vegetable protein increases the rate of bone loss and the risk of fracture in postmenopausal women. Study of Osteoporotic Fractures Research Group. Am J Clin Nutr 73:118-122

25. Zwart SR, Davis-Street JE, Paddon-Jones D, Ferrando AA, Wolfe RR, Smith SM 2005 Amino acid supplementation alters bone metabolism during simulated weightlessness. J Appl Physiol 99:134-140

26. Heaney RP, Layman DK 2008 Amount and type of protein influences bone health Am J Clin Nutr 87:1567S-1570S

27. Bourrin S, Ammann P, Bonjour JP, Rizzoli R 2000 Dietary protein restriction lowers plasma insulin-like growth factor I (IGF-I), impairs cortical bone formation, and induces osteoblastic resistance to IGF-I in adult female rats. Endocrinology 141:3149-3155

28. Straus DS, Burke EJ, Marten NW 1993 Induction of insulin-like growth factor binding protein-1 gene expression in liver of protein-restricted rats and in rat hepatoma cells limited for a single amino acid. Endocrinology 132:1090-1100

29. Isley WL, Underwood LE, Clemmons DR 1983 Dietary components that regulate serum somatomedin-C concentrations in humans. J Clin Invest 71:175-182 